INTERNATIONAL DESIGN CONFERENCE - DESIGN 2018

https://doi.org/10.21278/idc.2018.0500

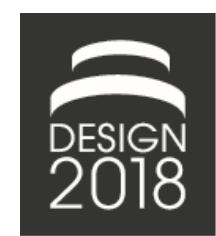

\title{
INVENTIVE PRODUCT DESIGN FOCUSING ON PHYSICAL CAUSAL RELATIONSHIPS CAUSING TRADE-OFFS BETWEEN FUNCTIONS
}

\author{
K. Oizumi and K. Aoyama
}

\begin{abstract}
Development of fascinating products has always been aspired by product designers. Trade-offs are one important aspects to consider improving a product functionality. When significant trade-off is relieved by a sort of invention, functionality of a product reaches new frontier. This paper proposes a method to support ideation of inventive solution based on analysis of trade-offs and physical contradictions in a product, which are mapped to contradiction matrix of TRIZ. Validity of the proposed method was confirmed through a demonstration with Continuous Variable Transmission.
\end{abstract}

Keywords: idea generation, early design phase, innovation management, TRIZ, complexity

\section{Introduction}

Development of fascinating products has always been an aspiration by product designers as it leads to competitive advantage for a company and brings about much higher value to customers. Therefore many companies invest in developments or inventions of new technologies. For successful investments in technologies, resources should be allocated strategically to targeted areas of products.

Trade-offs are one important aspects to consider when improving a product functionality. The parameters of several parts can contribute to improving an evaluation metric of a product. However, changing parts and/or their parameter may be impeded by the negative impact on other evaluation metrics. As there are many trade-offs in a product, they hinders improvement of a product. When a significant trade-off is improved by an invention, functionality of a product reaches new levels.

As recent products become so complex and integrated, it is difficult to find significant trade-offs. Therefore, a formal method to detect significant trade-offs and contemplate possible inventive solutions to mitigate them is required.

\section{Previous works}

There are several works that proposes methods to specify a part of a product where invention should be applied. Yamashina et al. $(2002,2005)$ proposed a method that enables to find parts of a product where technical invention should be applied. The method suggests the most effective attributes by means of Quality Function Deployment (QFD), in view of importance and technological difficulties. Then, an inventive solution is sought by means of TRIZ (Theory of Solving Inventive Problems in Russian acronym). Bariani et al. (2004) proposed to combine DFMA (Design for manufacture and assembly) and TRIZ for the purpose of reducing part count. By analysing the product through DFMA, problems of a product are specified. Though it refers to simplification of product structure, concern is more on manufacturing process than design process. Shirwaiker and Okudan (2008) proposed using TRIZ with the axiomatic design technique. Axiomatic design is recognized as a systematic method to analyse a 
product and to define a product's specific problems. TRIZ is applied as a method to generate inventive solutions for the defined problems. As axiomatic design technique encourages designers to decompose product hierarchy, problems could be specified in multiple scopes of a product. Yeh et al. (2011) integrated four-phase QFD and TRIZ. To find a contradiction, the roof of the house of quality (the part where interrelations between characteristics are depicted) is employed. To weigh contradictions, linear mapping of importance from requirements to characteristics, which is a traditional method in QFD, is applied. Based on contradictions specified, the contradiction matrix of TRIZ is applied to generate ideas. Baldussu et al. (2011) proposed a structured method to identify a critical control parameter that causes trade-off between evaluation parameters. In this method, a network of contradiction throughout the entire product is described. By evaluating contradictions in importance, universality and amplitude, critical contradiction and its control parameter are identified.

For those preceding works, propagation of change, which is an inherent problem of recent large-scale complex product systems, is not addressed. To tackle propagation of change, trade-offs need to be captured. Furthermore, inventive solutions should be discussed from the viewpoint of product architecture. That is, the potential of inventive solutions that alter product structure to mitigate change propagation. Change propagation is discussed in several works. Eckert et al. (2006) might be representative work, which proposed a method to calculate and comprehend change propagation.

\section{Inventive design process focusing on functional trade-offs}

As trade-offs play an important role in ideating inventive solutions for a product, this paper proposes a process to support product designers to specify significant trade-offs and ideate possible inventive solutions. The proposed inventive ideation process is as follows.

1. Modelling a product that depicts trade-offs (3.1)

2. Specifying significant trade-offs (3.2)

3. Describing physical causal relationships (3.3)

4. Ideating inventive solutions (3.4)

First, to describe a product depicting trade-offs between evaluation metrics, an extended house of quality proposed in (Oizumi and Aoyama, 2015) is employed. Second, significant trade-offs are specified based on analysis of change propagation caused by trade-offs. Third, to ideate possible inventive solutions which mitigate the specified trade-offs, causality of physical phenomena that leads to the trade-offs is further described. Finally, TRIZ is applied to the described physical causal relationships to ideate inventive solutions.

\subsection{Modelling a product that depicts trade-offs}

This paper proposes a product model as a basis for exploring where inventive solutions should be applied. As the proposed process focuses on mitigation of trade-offs, the product model has to capture trade-offs. As customers' concern is on function of a product, trade-offs between functions needs to be captured. Furthermore, as a technical invention is to be embodied as a physical part of a product, physical structure needs to be depicted as well. Therefore, functional and physical structures and their relationship need to be described on a product model. The house of quality is quite consistent with this prerequisite for a product model. As quality function deployment is a well-known and practical (especially in Japan) method, utilizing a house of quality may lower the barrier to implement the proposed process.

However, for a conventional house of quality, it is difficult to explain trade-offs between functions caused by design of physical parts, which is how a design parameter of a component causes trade-offs between functional measures. To solve this issue, this paper employs a product model that extends the house of quality proposed in (Oizumi and Aoyama, 2015). Brief definitions are as follows.

- Component: A component is a physical embodiment that composes a product. Each design parameter (explained below) belongs to one component. Each component has at least one design parameter.

- Design parameter: A design parameter is a parameter of a component that designer can determine. Design parameters affects functional metrics (explained below). Thus, design parameters are determined in order to achieve required levels of functional metrics. 
- Functional metric: A functional metric is a metric used to evaluate whether a product meets a certain functional requirement. To illustrate different strength of requirements importance is given to each functional metric.

Figure 1 shows an overview of an extended house of quality. To determine the effect of design parameter on a functional metric, sensitivity and characteristics are attributed. To ease data acquisition, sensitivity has two possible levels: 3) strong 1) not strong. Characteristics shows which direction a design parameter should be moved to improve a certain functional metric. There are four types: L) larger is better, S) smaller is better, C) closer is better and U) unknown. Here, 'Larger is better' means the larger the design parameter is, the better the functional metric would be.

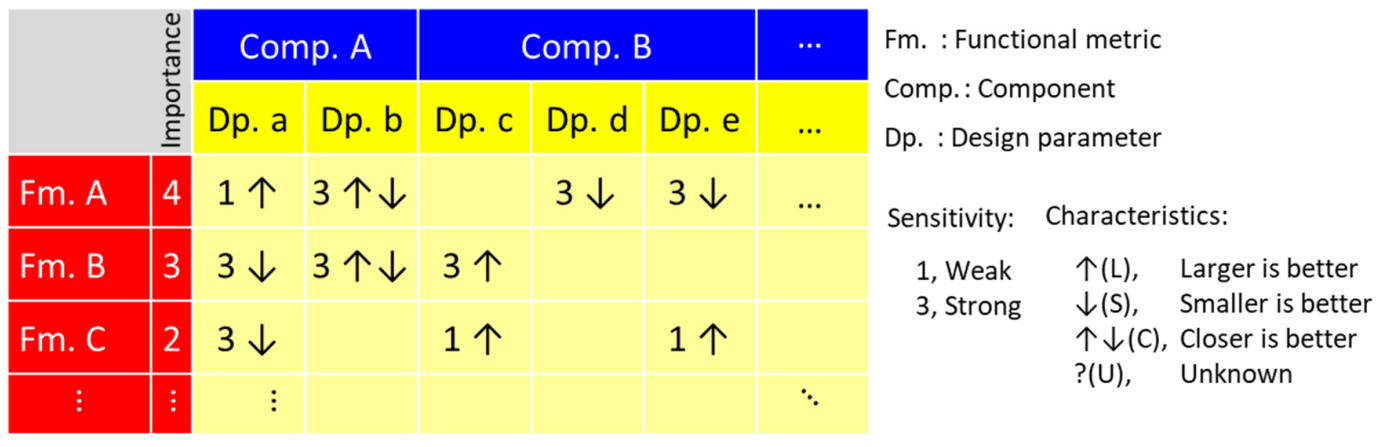

Figure 1. Extended house of quality

\subsection{Specifying significant trade-offs}

Parts of a product where inventive solutions is desired need to be specified. This paper focuses on tradeoffs between functional metrics as a clue to find parts of a product where inventive solutions should be applied. To evaluate the significances of trade-offs, change propagation analyses proposed in (Oizumi and Aoyama, 2012) are employed.

\subsubsection{Quantification of change propagation}

Change propagation is depicted as an expected propagation sensitivity DSM, which can be deduced from an extended house of quality as shown in Figure 2. When a design parameter is changed to improve a functional metric, it causes negative impact to another functional metric. By analysing sensitivities of functional metrics toward a design parameter, it is possible to calculate the strength of a propagated change from a functional metric to another. It is defined as a propagation sensitivity. There are several design parameters that can contribute to improving a certain functional metric. It is assumed that the probability of choosing each design parameter varies by the sensitivity. A propagation density represents this probability and is calculated as sensitivity of the functional metric to a design parameter divided by sum of sensitivity of the functional metric to all design parameters. A sum of a propagation sensitivity multiplied by a propagation density becomes expected propagation sensitivity, which resembles expected value in propagation theory. An expected propagation sensitivity DSM depicts expected propagation sensitivities from each functional metric to other functional metric.

\subsubsection{Specification of significant trade-offs contributing change propagation}

Due to the existence of trade-offs, changes propagate from a functional metric to other functional metrics. When a trade-off is resolved or mitigated, change propagates less than it used to. It may lead to improvements of functionality. Provided a trade-off is resolved, the trade-off structure of a product is changed. Therefore, the significance of a trade-off can be quantified as the extent of change propagation mitigation. To ease the calculation, the extent of change propagation is calculated by multiplication of an expected propagation sensitivity DSM. Here, the most significant trade-offs between functional metrics that cause the strongest propagation of change needs to be specified. 


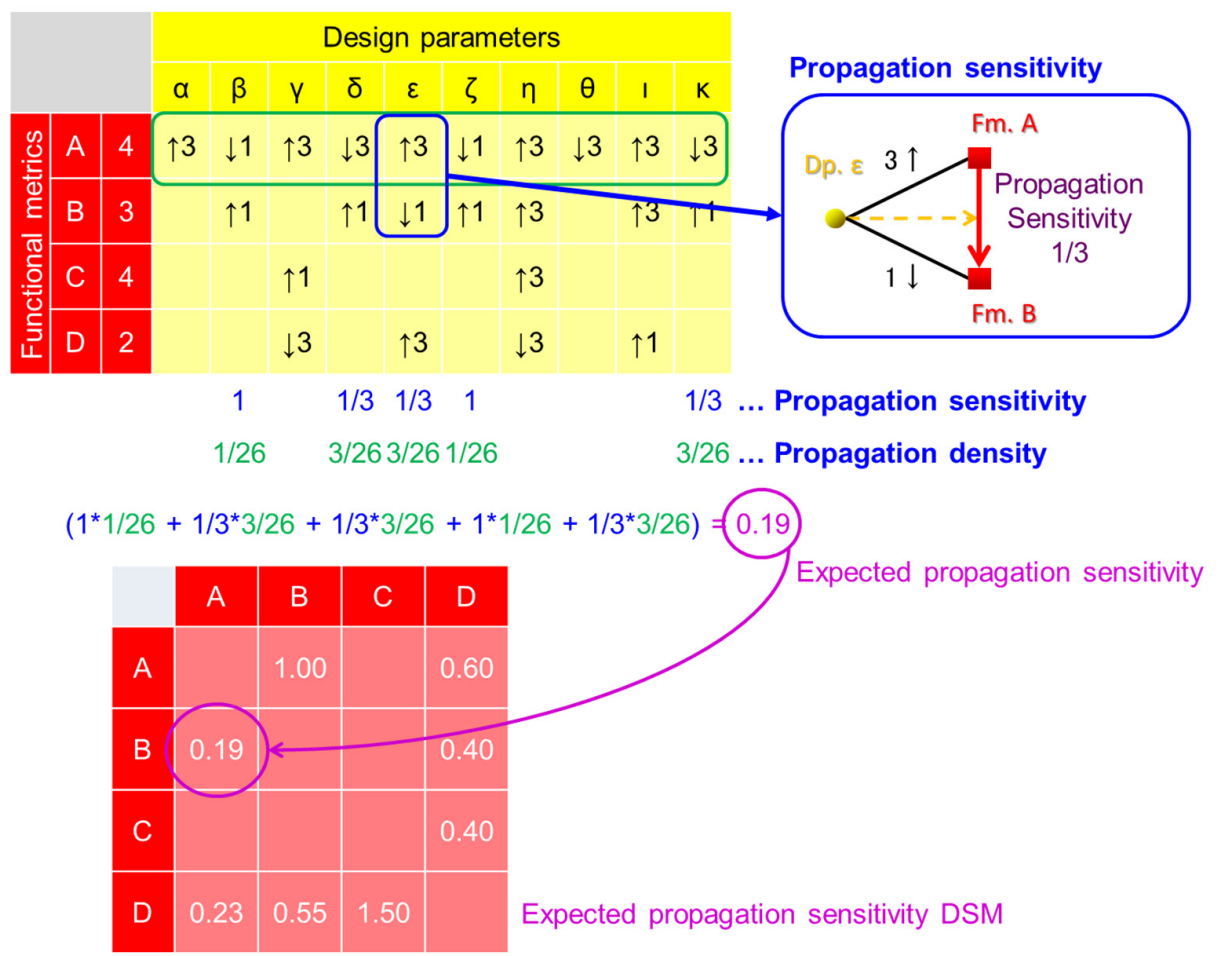

Figure 2. Calculation of expected propagation sensitivity

To analyse how each set of trade-offs between functional metrics contributes to propagation of change, propagation needs to be quantified. Here, matrix multiplication is employed as a way to calculate propagation of change. Multiplied propagation matrices of the original expected propagation sensitivity matrix and the same matrix without the tested trade-offs are compared as shown in Figure 3 a). The "R" matrix is a normalized expected propagation sensitivity matrix. To avoid divergence, the expected propagation sensitivity matrix is normalized by the largest sum of a row. When the matrix has n columns, $\mathrm{n}$-1 power of the matrix ("R $\mathrm{R}_{\text {total }}$ ") denotes propagated changes. For "R- $\mathrm{r}_{\mathrm{ij}}$ " matrix, trade-offs between functional metrics $i$ and $j$ are subdued from "R" matrix. Then, $n-1$ power of the matrix ("(R- $\left.r_{i j}\right)_{\text {total }}$ ") denotes propagated changes without the subdued trade-offs. Those trade-offs that causes larger difference between " $R_{\text {total }}$ " and "(R- $\left.r_{i j}\right)_{\text {total }}$ " has significant effects on the product, which should be investigated further.

The former analysis specifies significant sets of trade-offs in functional metric level. However, an effect of a design parameter on a functional metric is involved in several trade-offs because a design parameter has effects on several functional metrics. Therefore, how each effect of a design parameter on a functional metric contributes to the entire change propagation needs to be evaluated as well.

Here, the propagation analysis explained above is adjusted for design parameter level analysis. If an effect of a design parameter on a functional metric is resolved, how change propagation would be mitigated is calculated as shown in Figure $3 \mathrm{~b}$ ).

\subsection{Describing physical causal relationships}

Upon specifying trade-offs where inventive solution should be applied, physical phenomena causing the trade-offs are to be investigated. Thus, the physical causal relationship model between functional metrics and design parameters that are involved in the trade-offs needs to be described. The physical causal relationship model depicts physical parameters that are involved in relationships between design parameters and functional metrics. Dimensions are given to physical parameters in SI unit. Effects between physical parameters are described. Each effect has positive/negative and strength (given by strong or weak). Figure 4 shows example of physical causal relationship model. 


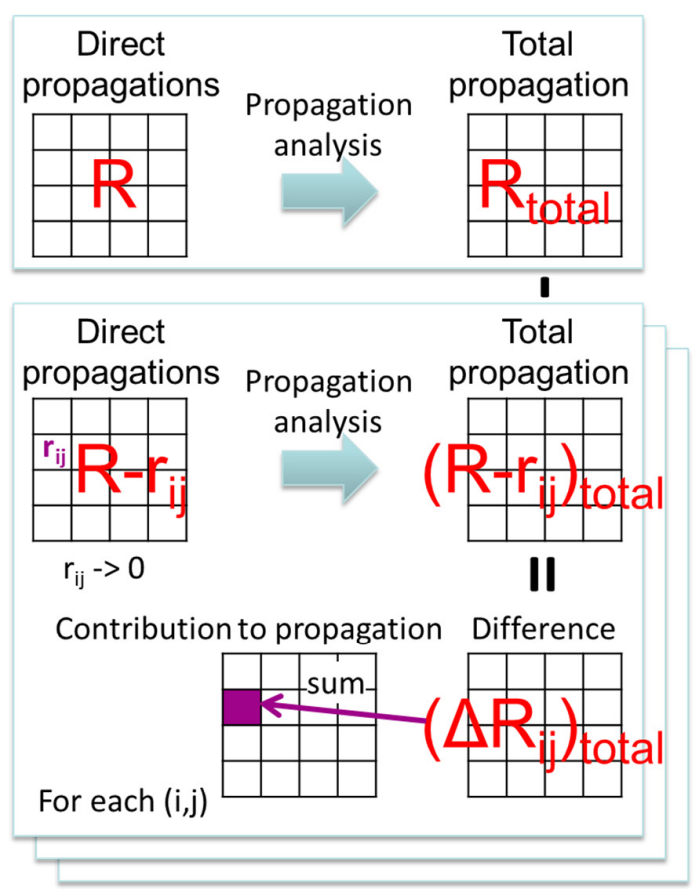

a) Functional metric level

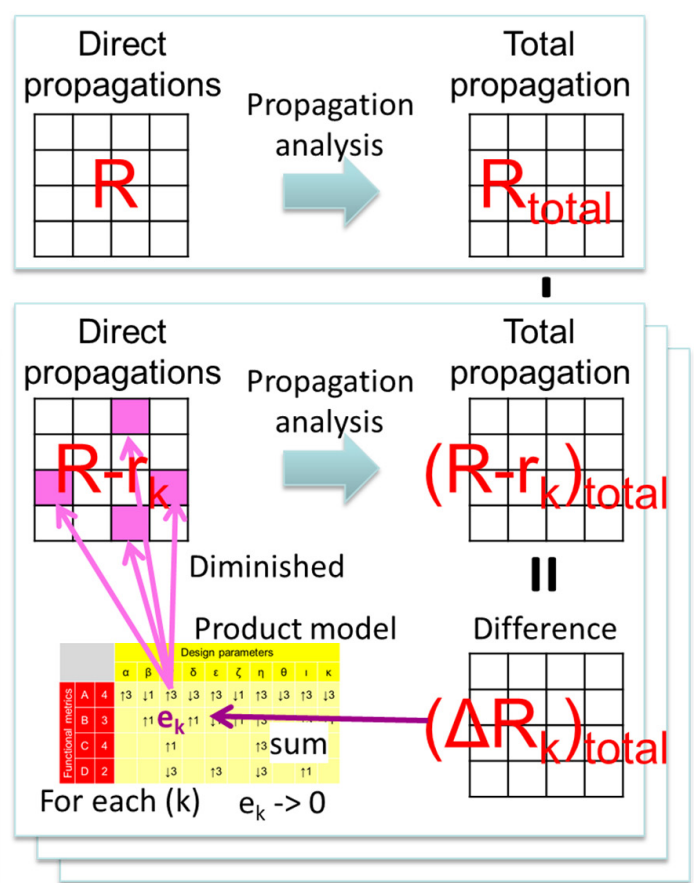

b) Design parameter level

Figure 3. Specification of significant trade-offs by propagation analysis

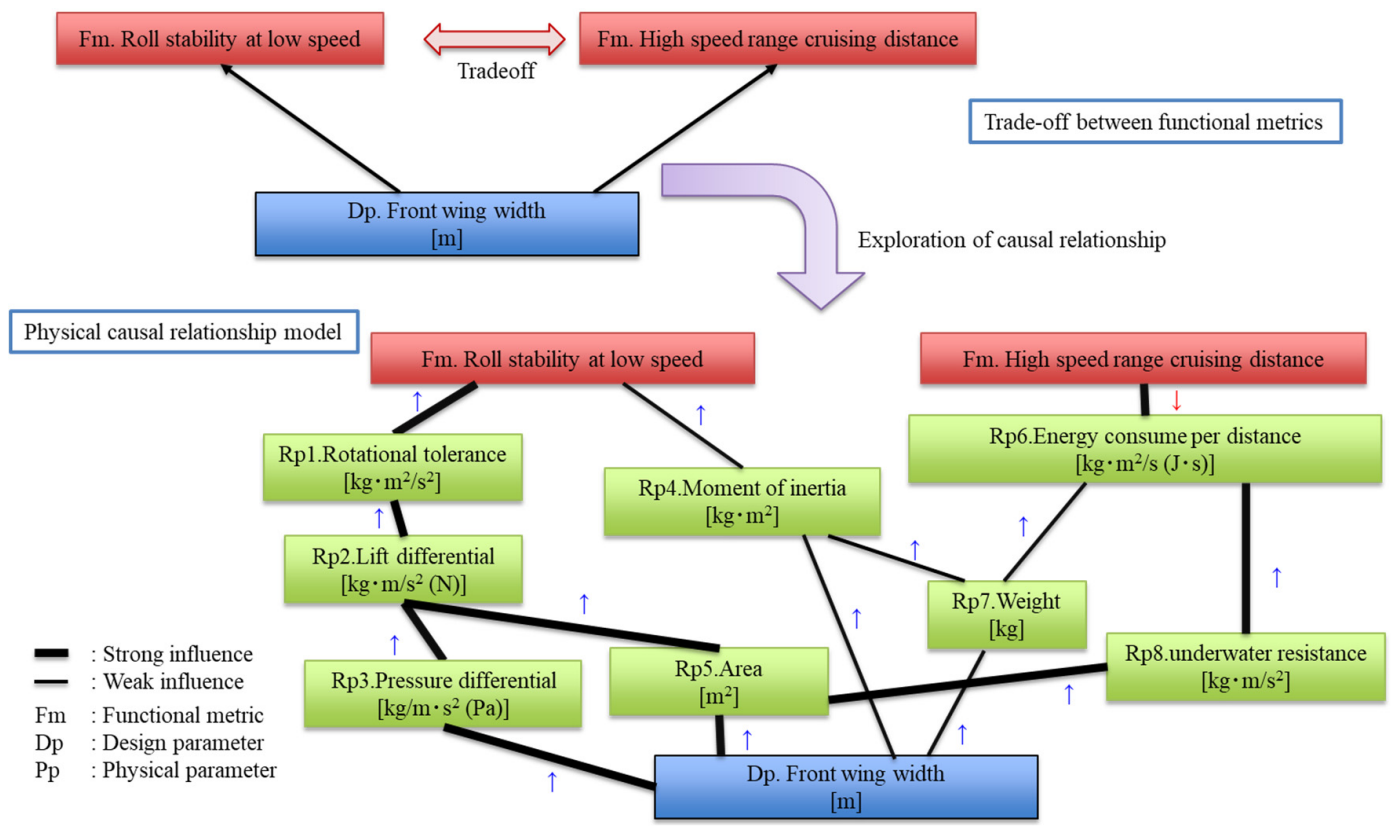

Figure 4. Physical causal relationship model

\subsection{Ideating inventive solutions}

To support ideation of inventive solution, TRIZ is employed. To apply TRIZ to the physical causal relationship model, this paper proposes the following three steps.

1. Application of contradiction matrix (3.4.1)

2. Prioritization of inventive principle (3.4.2)

3. Specification of focused physical contradiction (3.4.3) 
By suggesting inventive principles and focused physical contradictions in combination, designers try to ideate inventive solutions.

\subsubsection{Application of the contradiction matrix of TRIZ}

Physical contradictions are deduced from physical causal relationship model. Then, contradiction matrix of TRIZ is applied to each physical contradiction. The contradiction matrix suggests inventive principles applicable to a contradiction between an improving feature (row) and a worsening feature (column). To draw out inventive principles from the contradiction matrix, physical parameters in the physical causal relationship model needs to be mapped to improving and worsening features. To realize automatic mapping, SI units are given to both physical parameters and improving/worsening features. Table 1 shows several examples of SI unit dimensions given to improving/worsening features.

Table 1. SI unit dimensions for improving/worsening features

\begin{tabular}{ll|ll} 
Physical principles & Dimension & Physical principles & Dimension \\
\hline 1. Weight of moving object & $\mathrm{kg}$ & 7. Volume of moving object & $\mathrm{m}{ }^{\wedge} 3$ \\
3. Length of moving object & $\mathrm{m}$ & 10. Force (Intensity) & $\mathrm{kg} \cdot \mathrm{m} / \mathrm{s}^{\wedge} 2$ \\
5. Area of moving object & $\mathrm{m}^{\wedge} 2$ & 19. Use of energy by moving object & $\mathrm{kg} \cdot \mathrm{m}^{\wedge} 2 / \mathrm{s}^{\wedge} 2$
\end{tabular}

As shown in Figure 5, several inventive principles can be retrieved from the contradiction matrix. In the case of Figure 5, the physical parameter "Resilience" can be mapped to the improving features "Use of energy by moving object", "Use of energy by stationary object", "Power" or "Loss of energy". Likewise, the physical parameter "Area" can be mapped to the worsening features "Area of moving object" or "Area of stationary object". By taking "Use of energy by moving object" and "Area of moving object" for instance, the inventive principles 19, "Periodic action", and 32, "Changing colour or optical properties", are suggested. As functional metrics are in trade-off, physical parameters that are related to the functional metrics should have contradictions as well. Thus, all possible physical contradictions can be deduced from the physical causal relationship model.

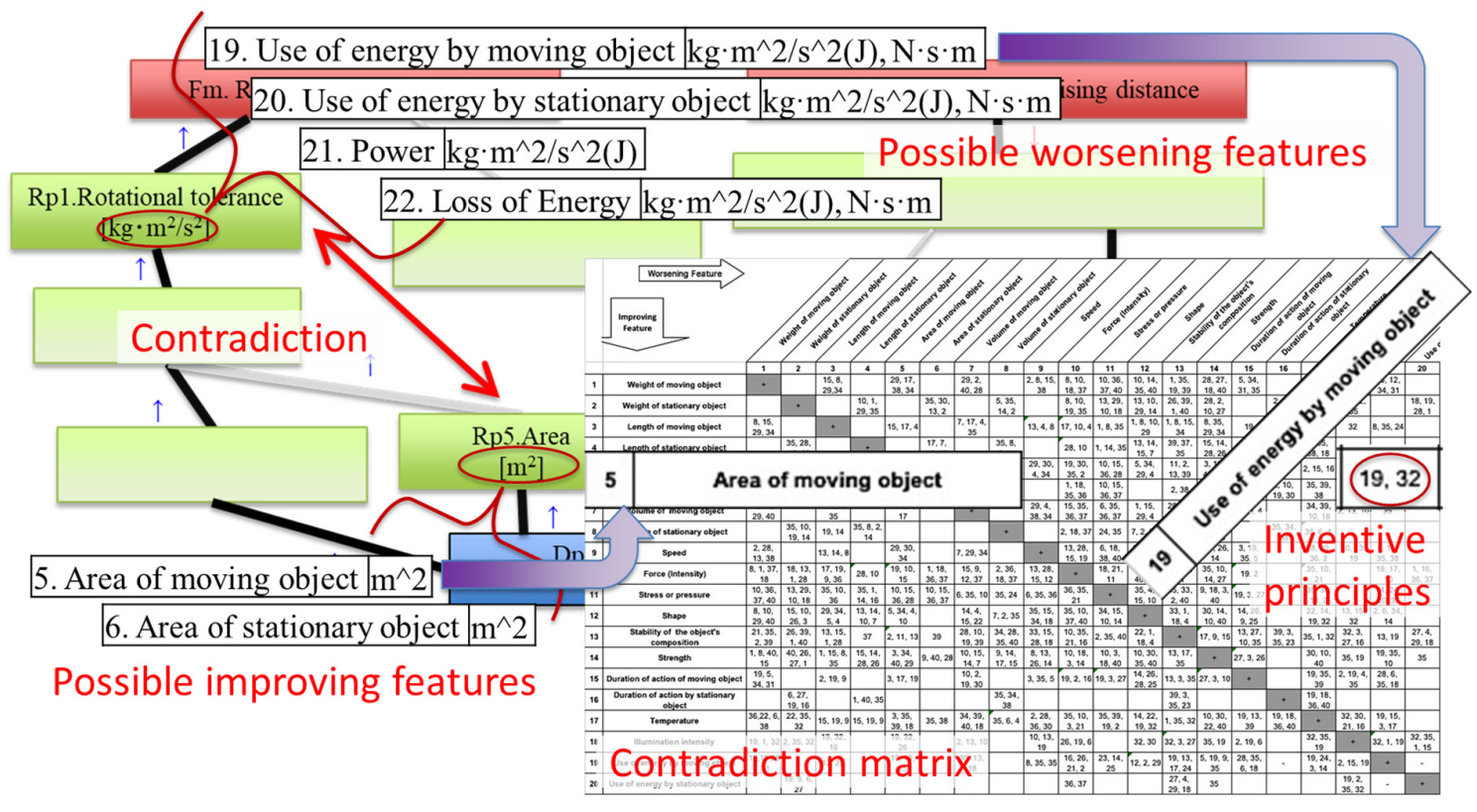

Figure 5. Retrieval of inventive principles through mapping between physical parameters and improving/worsening features 


\subsubsection{Prioritization of inventive principles}

As many inventive principles are drawn from the contradiction matrix, those principles should have priority among them. Each cell of contradiction matrix has at most 4 inventive principles, where earlier principle is prior to later ones. Thus, a priority weighting is given to each inventive principle in 4, 3,2, or 1 according to the order of the principle appear in a cell.

Many physical contradictions are deduced from the physical causal relationship model. Furthermore, contradiction between improving and worsening features counts up even more. To each contradiction, several inventive principles are drawn. Thus, the sum of priority weighting is calculated for each inventive principle. Finally, those points are normalized by the number of each inventive principle appears in the contradiction matrix. Because there are large disparities in numbers of inventive principles in the contradiction matrix, less frequently-appearing principles could also be prioritized.

\subsubsection{Specification of focused physical contradiction}

In the previous step, inventive principles are suggested in prioritized order. Even if an inventive principle is determined, there are several physical contradictions that lead to the suggestion of the inventive principle. Within physical contradictions, significant ones should be mitigated. Significance of physical contradiction is calculated by strength of contribution of a physical parameter to a functional metric, which can be judged from the strength of relationships on the physical causal relationship model.

\section{Case study}

In this section, the proposed process is demonstrated in an example of Continuous Variable Transmission (CVT). A house of quality of the CVT is described as shown in Table 2.

Table 2. Extended house of quality depicting CVT

\begin{tabular}{|c|c|c|c|c|c|c|c|c|c|c|c|c|c|}
\hline & & \multicolumn{12}{|c|}{ Design Parameter } \\
\hline & & \multicolumn{3}{|c|}{ Pulley } & \multicolumn{2}{|c|}{ Belt } & \multicolumn{2}{|c|}{ Torque Converter } & \multicolumn{5}{|c|}{ Hydraulic Unit } \\
\hline Functional metrics & Importance & $\begin{array}{l}\text { Radius } \\
\text { ratio }\end{array}$ & $\begin{array}{l}\text { Sieving } \\
\text { angle }\end{array}$ & $\begin{array}{c}\text { Revolving } \\
\text { speed }\end{array}$ & $\begin{array}{c}\text { Surface } \\
\text { roughness }\end{array}$ & Strength & $\begin{array}{l}\text { Lock-up } \\
\text { speed }\end{array}$ & $\begin{array}{l}\text { Torque } \\
\text { ratio }\end{array}$ & $\begin{array}{l}\text { Area of } \\
\text { piston }\end{array}$ & $\begin{array}{c}\text { Amount of } \\
\text { oil }\end{array}$ & $\begin{array}{l}\text { Viscosity } \\
\text { of oil }\end{array}$ & $\begin{array}{c}\text { Coefficient } \\
\text { of friction }\end{array}$ & $\begin{array}{l}\text { Pushing } \\
\text { force }\end{array}$ \\
\hline Ratio & 9 & $3 \_\uparrow$ & - & - & - & - & - & - & - & - & - & - & - \\
\hline $\begin{array}{l}\text { Readiness for } \\
\text { transmission }\end{array}$ & 9 & - & $2 \_\uparrow$ & $2 \_\uparrow$ & $3 \_\downarrow$ & - & $3 \_\uparrow$ & $3 \_\uparrow$ & - & - & - & - & - \\
\hline $\begin{array}{l}\text { Operability for } \\
\text { transmission }\end{array}$ & 7 & - & - & - & $2 \_\uparrow$ & - & $3 \_\downarrow$ & - & - & - & - & - & - \\
\hline $\begin{array}{l}\text { Stability for normal } \\
\text { running }\end{array}$ & 6 & - & - & - & $3 \_\uparrow$ & - & - & - & - & - & - & - & $2 \_\uparrow$ \\
\hline Fuel economy & 9 & - & - & - & $2 \_\uparrow$ & - & $2 \_\uparrow$ & - & $1 \_\uparrow$ & $2 \_\downarrow$ & $2 \_\downarrow$ & $2 \_\uparrow$ & - \\
\hline Power efficiency & 8 & - & $1 \_\uparrow$ & $3 \_\uparrow$ & 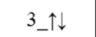 & - & $3 \_\uparrow$ & $3 \_\uparrow$ & $2 \_\uparrow$ & - & - & - & 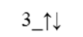 \\
\hline Load & 6 & - & - & $2 \_\uparrow$ & $3 \_\uparrow$ & $3 \_\uparrow$ & - & - & $1 \_\uparrow$ & - & - & - & $3 \_\uparrow$ \\
\hline Durability & 5 & - & $3 \_\downarrow$ & $2 \_\uparrow$ & $3 \_\downarrow$ & $3 \_\uparrow$ & - & - & $3 \_\uparrow$ & $3 \_\downarrow$ & - & - & $1 \_\downarrow$ \\
\hline
\end{tabular}

\subsection{Demonstration of proposed method}

First of all, significant trade-offs are explored at the functional metric level. Figure 6 shows contributions of trade-offs between functional metrics. As shown in Figure 6, the trade-off between "Operability for transmission" (Fm3) and "Readiness for transmission" (Fm2) and the trade-off between "Stability for normal running" (Fm4) and "Power efficiency" (Fm6) are suggested as the most significant trade-offs. 


\begin{tabular}{|c|c|c|c|c|c|c|c|c|c|}
\hline & & $\begin{array}{l}\text { त्ञㅁ․ } \\
\text {. }\end{array}$ & 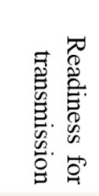 & 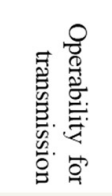 & 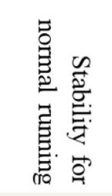 & 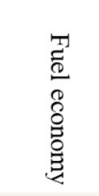 & 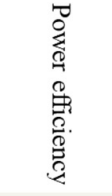 & $\begin{array}{l}5 \\
\stackrel{0}{2}\end{array}$ & 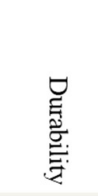 \\
\hline & & fn1 & fn2 & fn3 & fn4 & fn5 & fn6 & $\mathrm{fn} 7$ & fn8 \\
\hline Ratio & $\mathrm{fn} 1$ & 0.0 & 0.0 & $\rho . \theta$ & 0.0 & 0.0 & 0.0 & 0.0 & 0.0 \\
\hline Readiness for transmission & $\mathrm{fn} 2$ & 0.0 & 0.0( & 0.94 & b.455 & 0.195 & 0.234 & 0.201 & 0.128 \\
\hline perability for transmission & $\mathrm{fn} 3$ & 0.0 & 0.58 & $\sigma . \sigma$ & 0.0 & 0.275 & 0.541 & 0.0 & 0.18 \\
\hline Stability for normal running & fn4 & 0.0 & 0.319 & 0.0 & 0.0 & 0.0 & 0.481 & 0.0 & 0.396 \\
\hline Fuel economy & fn5 & 0.0 & 0.15 & 0.285 & 20 & 0.0 & 0.138 & 0.0 & 0.113 \\
\hline Power efficiency & fn6 & 0.0 & 0.263 & 0.823 & 0.924 & 0.202 & 0.0 & 0.411 & 0.456 \\
\hline Load & $\mathrm{fn} 7$ & 0.0 & 0.216 & 0.0 & 0.0 & 0.0 & 0.396 & 0.0 & 0.324 \\
\hline Durability & fn8 & 0.0 & 0.239 & 0.457 & 0.566 & 0.184 & 0.508 & 0.25 & 0.0 \\
\hline
\end{tabular}

Figure 6. Physical causal relationship model

Then, these trade-offs are investigated at design parameter level. "Surface roughness" of "Belt" and "Lock-up speed" of "Torque converter" are recognized as strongly contributing design parameters for the trade-off between "Operability for transmission" and "Readiness for transmission" (Figure 7 a)). Likewise, "Surface roughness" of "Belt" and "Pushing force" of "Hydraulic unit" are recognized as strongly contributing design parameters for the trade-off between "Stability for normal running" and "Power efficiency".

As a result, the following trade-offs are selected for further investigation.

- Trade-off between "Operability for transmission" and "Readiness for transmission" caused by "Lock-up speed" of "Torque converter"

- Trade-off between "Stability for normal running" and "Power efficiency" caused by "Surface roughness" of "Belt"

For the trade-offs above, the physical causal relationship models are described. Figure 7 b) shows the physical causal relationship model made to the first trade-off specified as Figure 7 a). By applying the contradiction matrix to them, inventive principles and physical contradictions relevant for each principle are suggested as shown in Figure 8 and Figure 9.

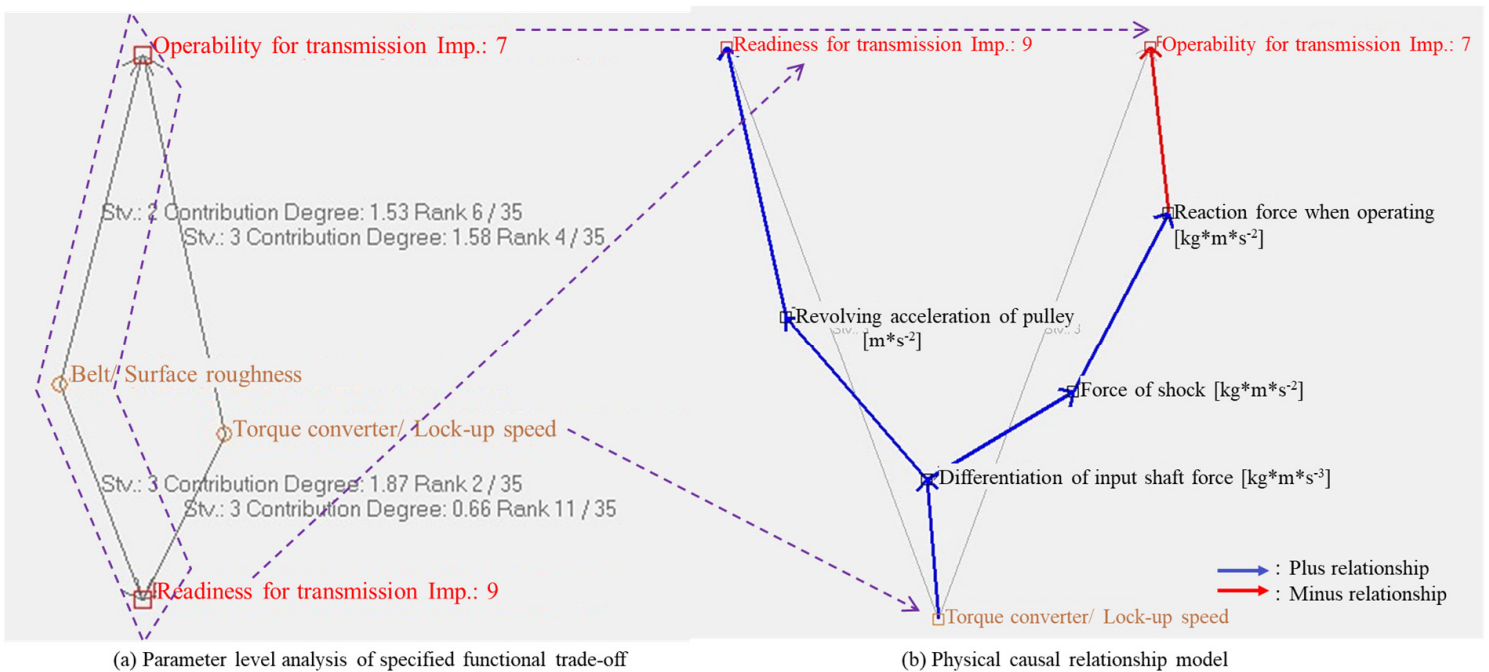

Figure 7. Physical causal relationship model constructed to a specified trade-off between functional metrics caused by a design parameter 


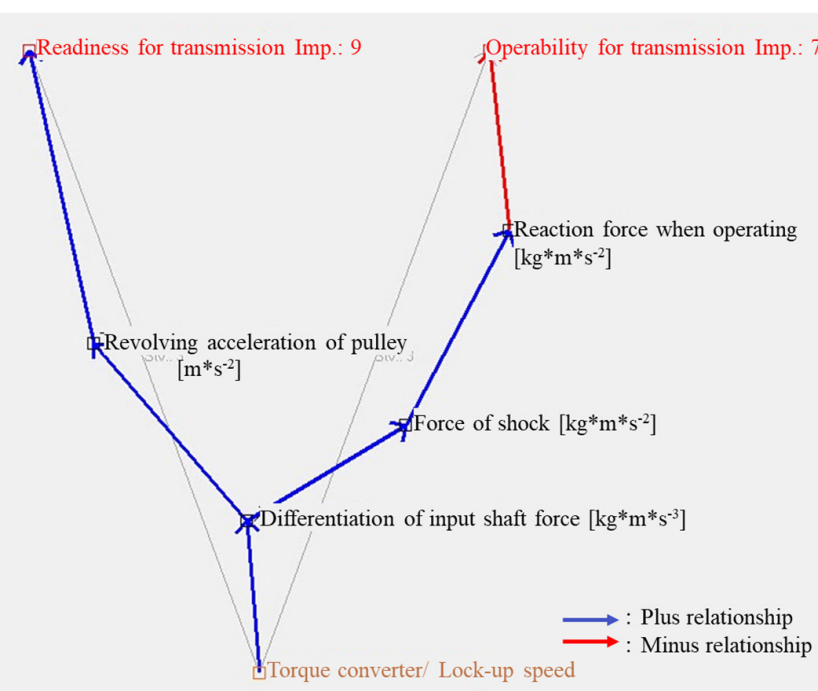

\begin{tabular}{|c|c|c|}
\hline \multicolumn{3}{|c|}{ Inventive Principles } \\
\hline Rank & $\begin{array}{l}\text { Irventive } \\
\text { principle }\end{array}$ & Score \\
\hline 1 & 8 & 5.04878 \\
\hline 2 & 12 & 3.36364 \\
\hline 3 & 36 & 3.33871 \\
\hline 4 & 38 & 2.375 \\
\hline 5 & 9 & 2.33333 \\
\hline 6 & 6 & 2.08537 \\
\hline 7 & 17 & 2.08333 \\
\hline $\begin{array}{l}8 \\
<\end{array}$ & 10 & $\underset{>}{2 n 7 \cap a 7}$ \\
\hline
\end{tabular}

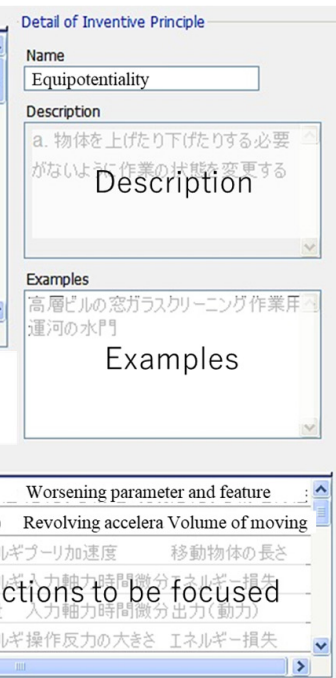

(a) Physical causal relationship model

(b) Result of proposed inventive principles and related physical features

Figure 8. Retrieval of inventive principles based on describing physical causal model for trade-off between "Operability for transmission" and "Readiness for transmission" caused by Lock-up speed of Torque converter

In the case of Figure 8, for example, "Equipotentiality" is suggested as one of most relevant inventive principles. Then, the physical contradiction between "Differentiation of input shaft force" and "Revolving acceleration of pulley" is suggested as a basis for contemplating inventive solutions. As a result, for instance, preliminary revolving output shaft is ideated.

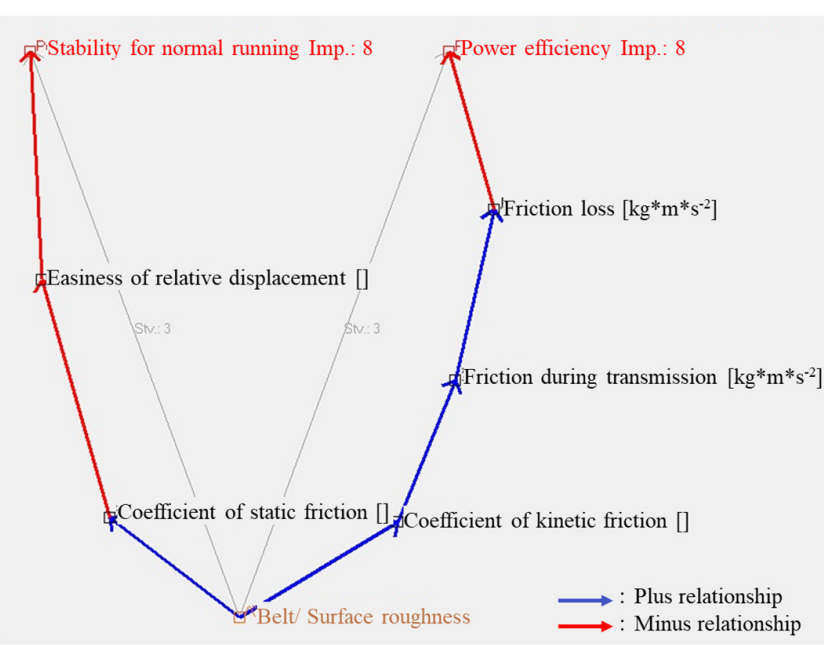

(a) Physical causal relationship model

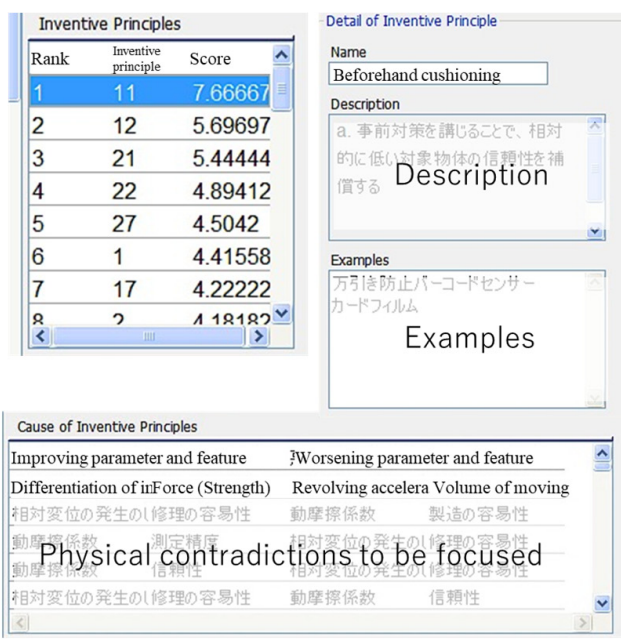

(b) Result of proposed inventive principles and related physical features

Figure 9. Retrieval of inventive principles based on describing physical causal model for trade-off between "Stability for normal running" and "Power efficiency" caused by "Surface roughness" of "Belt"

In the case of Figure 9, inventive principles such as "Beforehand cushioning", and improving/worsening features "Ease for production" and "Ease of restoration are suggested". However, relevant solution could not be ideated.

\subsection{Discussion}

Through the example shown in Figure 8, it was confirmed that the proposed method suggested relevant inventive principles and led to ideation of a solution. Therefore, the proposed method successfully supports designers ideating inventive solutions, in certain cases. 
As for the example shown in Figure 9, though several inventive principles are suggested, the relevance of principles was questionable. As shown in Figure 9, several physical parameters in this case have no dimension. Thus, mapping to the contradiction matrix could not be sufficiently relevant. Therefore, it seems the inventive principles suggested were also irrelevant. Thus, mapping between physical parameters in the physical causal relationship model and improving/worsening features in the contradiction matrix should be improved. For example, the use of tags that conceptualizes physical phenomena could be applied. By this kind of development, it is considered that applicability of the proposed method would be further improved.

As for the applicability of the proposed method, though it is still controversial, the demonstration by the CVT shows relevance to mechatronics products. In the case of CVT, only physical components are listed. However, design parameters integrates the software parts of the product. For example, the design parameter "Lock-up speed" of "Torque converter" involves parameters of the software that control pressure regulating valves sending working fluids to "Torque converter". Thus, the software parts could be implied in the extended house of quality. The validity of this implication has to be further tested with other products.

\section{Conclusion}

In this paper, a method to support ideation of inventive solutions is proposed based on analysis of tradeoffs and physical contradictions in a product. Use of the house of quality contributes to specifying significant functional trade-offs in a product. The physical causal relationship model contributes to further clarification of physical phenomena, which enables mapping to the contradiction matrix of TRIZ. To evaluate the validity of the proposed method an example of a CVT was given. As a result, in certain conditions where physical parameters could have relevant dimensions to be mapped to improving/worsening features, relevant inventive principles are suggested. To further improve the applicability of the proposed method, a method to map between physical parameters and improving/worsening features of the contradiction matrix should be developed.

\section{References}

Baldussu, A., Becattini, N. and Cascini, G. (2011), "Network of contradictions analysis and structured identification of critical control parameters", Procedia Engineering, Vol. 9, pp. 3-17.

Bariani, P.F., Lucchetta, G. and Berti, G. (2004), "A Combined DFMA and TRIZ approach to the simplification of product structure", Proceedings of the Institution of Mechanical Engineers, Part B: Journal of Engineering Manufacture, Vol. 218 No. 8, pp. 1023-1027.

Eckert, C.M., Keller, R., Earl, C. and Clarkson, P.J. (2006), "Supporting change processes in design: complexity, prediction and reliability", Reliability Engineering and System Safety, Vol. 91 No. 12, pp. 1521-1534.

Oizumi, K. and Aoyama, K. (2012), "Functional structure based change assessment in product design", Proceedings of 14th International DSM Conference, Kyoto, Japan, September 13-14, 2012, The Design Society.

Oizumi, K. and Aoyama, K. (2015), "Comprehending Design Change Propagation by Utilizing Information on Quality Function Deployment”, Journal of Japan Society for Design Engineering, Vol. 50 No. 11, pp. 35-44. (in Japanese)

Shirwaiker, R.A. and Okudan, G.E. (2008), "Triz and axiomatic design: a review of case-studies and proposed synergistic use”, Journal of Intelligent Manufacturing, Vol. 19 No. 1, pp. 33-47.

Yamashina, H., Ishida, K. and Mizuyama, H. (2005), “An Innovative Product Development Process for Resolving Fundamental Conflicts", Journal of the Japan Society for Precision Engineering, Vol. 71 No. 2, pp. 216-222.

Yamashina, H., Ito, T. and Kawada, H. (2002), "Innovative Product Development Process by Integrating QFD and TRIZ", International Journal of Production Research, Vol. 40 No. 5, pp. 1031-1050.

Yeh, C.H., Huang, J.C.Y. and Yu, C.K. (2011), "Integration of four-phase QFD and TRIZ in product R\&D: a notebook case study”, Research in Engineering Design, Vol. 22 No. 1, pp. 125-141.

Dr. Kazuya Oizumi, Assistant Professor

The University of Tokyo, Department of Systems Innovation

7-3-1 Hongo, 113-8656 Bunkyo-ku, Japan

Email: oizumi@m.sys.t.u-tokyo.ac.jp 